\title{
Correction to: Effect of fracturoscopy on the incidence of surgical site infections post tibial plateau fracture surgery
}

\author{
Ralf Henkelmann ${ }^{1}$ (1) . Matthias Krause ${ }^{2} \cdot$ Lena Alm $^{3} \cdot$ Richard Glaab $^{9} \cdot$ Meinhard Mende $^{4} \cdot$ Christopher UII $^{6}$. \\ Philipp-Johannes Braun ${ }^{7}$. Christoph Katthagen ${ }^{8} \cdot$ Tobias J. Gensior $^{5,10} \cdot$ Karl-Heinz Frosch $^{2} \cdot$ Pierre Hepp ${ }^{1}$
}

Published online: 20 October 2020

(c) The Author(s) 2020

\section{Correction to: \\ European Journal of Trauma and Emergency Surgery https://doi.org/10.1007/s00068-020-01486-y}

The original version of this article unfortunately contained a mistake. In the author list, the first and last names were tagged incorrectly. The corrected author list is given above.

The original article has been corrected.
The original article can be found online at https://doi.org/10.1007/ s00068-020-01486-y.

Ralf Henkelmann

ralf.henkelmann@medizin.uni-leipzig.de

1 Department of Orthopedics, Trauma and Plastic Surgery, University of Leipzig, Liebigstraße 20, 0410 Leipzig, Germany

2 Clinic of Trauma, Hand and Reconstructive Surgery, University Medical Center Hamburg-Eppendorf, Hamburg, Germany

3 Division of Knee and Shoulder Surgery, Department of Trauma and Reconstructive Surgery, Sports Traumatology, Asklepios Klinik St. Georg, Hamburg, Germany

4 Centre for Clinical Trials, University of Leipzig, Leipzig, Germany
Open Access This article is licensed under a Creative Commons Attribution 4.0 International License, which permits use, sharing, adaptation, distribution and reproduction in any medium or format, as long as you give appropriate credit to the original author(s) and the source, provide a link to the Creative Commons licence, and indicate if changes were made. The images or other third party material in this article are included in the article's Creative Commons licence, unless indicated otherwise in a credit line to the material. If material is not included in the article's Creative Commons licence and your intended use is not permitted by statutory regulation or exceeds the permitted use, you will need to obtain permission directly from the copyright holder. To view a copy of this licence, visit http://creativecommons.org/licenses/by/4.0/.

5 Clinic for Arthroscopic Surgery, Sports Traumatology and Sports Medicine, BG Clinic, Duisburg, Germany

6 Department of General and Trauma Surgery, BG University Hospital Bergmannsheil, Bochum, Germany

7 Department of Trauma and Orthopaedic Surgery, BG Hospital Unfallkrankenhaus Berlin gGmbH, Berlin, Germany

8 Department of Trauma, Hand and Reconstructive Surgery, University Hospital Münster, Münster, Germany

9 Department of Traumatology, Cantonal Hospital Aarau, Aarau, Switzerland

10 Orthopädische Praxisklinik Neuss-Düsseldorf (OPND), Düsseldorf, Germany 